\title{
Characteristics and nutrient intake of Taiwanese elderly vegetarians: evidence from a national survey
}

\author{
Chun-Jen Huang ${ }^{1,2,3}$, Yen-Chun Fan ${ }^{1}$, Jen-Fang Liu ${ }^{4}$ and Pei-Shan Tsai ${ }^{5,6,7 *}$ \\ ${ }^{1}$ Department of Anesthesiology, Buddhist Tzu Chi General Hospital, Taipei Branch, Taipei, Taiwan, ROC \\ ${ }^{2}$ School of Medicine, Tzu Chi University, Hualien, Taiwan, ROC \\ ${ }^{3}$ School of Medicine, Taipei Medical University, Taipei, Taiwan, ROC \\ ${ }^{4}$ School of Nutrition and Health Sciences, Taipei Medical University, Taipei, Taiwan, ROC \\ ${ }^{5}$ Graduate Institute of Nursing, College of Nursing, Taipei Medical University, 250 Wu Hsing Street, Taipei 110, Taiwan, ROC \\ ${ }^{6}$ Department of Nursing, Wan Fang Hospital, Taipei Medical University, Taipei, Taiwan, ROC \\ ${ }^{7}$ Sleep Science Center, Taipei Medical University Hospital, Taipei, Taiwan, ROC
}

(Received 9 August 2010 - Revised 9 December 2010 - Accepted 28 December 2010 - First published online 9 March 2011)

\section{Abstract}

The present study examines the prevalence and characteristics of vegetarians in the Taiwanese elderly. We analysed data from the Elderly Nutrition and Health Survey in Taiwan (1999-2000), which used a multi-staged, stratified, clustered probability sampling design. Communitydwelling elderly ( $n$ 1071), aged 65 years and older, were included. Sociodemographic, anthropometric, lifestyle and metabolic variables, and eating habits were obtained through household interviews and health examinations. Nutrient intake was assessed using a $24 \mathrm{~h}$ dietary recall. Multivariable logistic regression analysis was performed to examine factors significantly and independently associated with vegetarian status and to estimate the OR of the hypertension and the metabolic syndrome (MS) for vegetarians compared with omnivores. About $25 \%$ of the Taiwanese elderly persons were vegetarians. Systolic pressure (OR 1.01, 95\% CI 1, 1.02, $P=0 \cdot 038$ ), female sex (OR 5.02, $95 \%$ CI 3.11, 8.1, $P<0 \cdot 001$ ), smoking status ( $P=0 \cdot 034$; current smoker (OR 0.45, $95 \%$ CI $0 \cdot 24,0 \cdot 85, P=0 \cdot 014)$ ) and regular exercise (OR 1.87, $95 \%$ CI 1·37, 2.56, $P<0 \cdot 001$ ) were independently associated with vegetarian status among Taiwanese elderly persons. Vegetarians consumed significantly lower daily total energy $(P<0 \cdot 001)$, lower cholesterol $(P=0 \cdot 002)$, a higher percentage of fat as PUFA $(P=0 \cdot 022)$, higher $\mathrm{Ca}(P<0.001)$ and higher crude fibres $(P=0.041)$ compared with omnivores. Between the two vegetarian diets, ovo- or lactovegetarian diets contained more beneficial micronutrients, such as $\mathrm{K}, \mathrm{Ca}$ and $\mathrm{Mg}$, and higher crude fibres than vegan diets (all $P<0.05$ ). The likelihood of having hypertension and the MS was not significantly different between vegetarians and omnivores as examined by sexor multivariate-adjusted logistic regression.

Key words: Elderly: Metabolic profile: Nutrient intake: Vegetarians

According to the American Dietetic Association, a vegetarian diet is defined as a diet that does not contain meat or seafood or products containing those foods ${ }^{(1)}$. Accumulating evidence suggests that vegetarian diets are associated with a lower rate of CHD and hypertension in Western countries ${ }^{(2-4)}$. However, the features of a vegetarian diet or a vegetarian lifestyle that are responsible for the blood pressure (BP)-lowering effect remain poorly understood ${ }^{(1)}$. Vegetarianism and religions are strongly linked. In Taiwan, many of the followers of vegetarianism, also known as 'su vegetarians', are religious followers of Buddhism. Thus, it is likely that these vegetarians not only adopt a vegetarian diet but also live a lifestyle that is very different from omnivores.
'Su vegetarians' strictly adhere to a vegan diet and completely omit all foods of animal sources, as well as fetid vegetables, such as garlic and shallots. The modern 'su vegetarian' diet allows dairy products and/or eggs (i.e. lactovegetarians or ovo-lacto vegetarians). According to the findings from the 1993-6 Nutrition and Health Survey in Taiwan, the proportion of vegetarians in individuals whose age was 65 years and above was sizeable; 3 and $20 \cdot 1 \%$ in male elderly and female elderly, respectively ${ }^{(5)}$. It is thus of interest to unveil the sociodemographic and lifestyle characteristics of elderly vegetarians in Taiwan.

Taiwanese diets include rice (as the staple food), vegetables, fruits, seafood, meat and poultry ${ }^{(5)}$. The only

Abbreviations: BP, blood pressure; GLM, generalised linear model; JNC, Joint National Committee; MS, metabolic syndrome.

*Corresponding author: P.-S. Tsai, fax +886223772842, email ptsai@tmu.edu.tw 
difference with a Taiwanese vegetarian diet is that seafood, meat and poultry in the usual Taiwanese diet are substituted with soyabeans and soya products ${ }^{(6)}$. Although meal pattern and cooking methods of Taiwanese vegetarian diets are similar to usual Taiwanese diets, Taiwanese who were on an ovolacto-vegetarian diet had a better cardiovascular risk profile (e.g. lower total cholesterol, LDL-cholesterol and C-reactive protein levels, and higher homocysteine levels) than their omnivore counterparts, according to a study analysing a convenience sample of 198 healthy adults ${ }^{(7)}$. In addition, Taiwanese vegetarians were found to be more insulin-sensitive than omnivores in middle-aged or young adults ${ }^{(8,9)}$. However, contradicting to evidence from Western countries, vegetarian diets were not associated with hypertension status in a study investigating factors associated with hypertension in elderly persons in Southern Taiwan ${ }^{(10)}$. Moreover, a recent study demonstrated that Taiwanese elderly vegetarians had metabolic characteristics that were not significantly different from the omnivores ${ }^{(11)}$.

In the light of the inconclusiveness of the available evidence with respect to the beneficial effects of Taiwanese vegetarian diets, it is important to seek evidence from a well-representative sample. Therefore, the purpose of this population-based study was fourfold: (1) to estimate the prevalence of different types of vegetarians in the Taiwanese elderly population, (2) to examine the sociodemographic, lifestyle and metabolic characteristics of elderly vegetarians in Taiwan, (3) to determine the likelihood (i.e. OR) of hypertension for vegetarians compared with those who are not vegetarians after adjusting for potential confounders and (4) to determine the OR of the metabolic syndrome (MS) for vegetarians compared with those who are not vegetarians after adjusting for potential confounders.

\section{Methods}

\section{Study sample}

We analysed data from the Elderly Nutrition and Health Survey in Taiwan (1999-2000), which used a multi-staged, stratified, clustered probability sampling design ${ }^{(12,13)}$. Briefly, probabilities were determined based on the age-sex and residence stratum of eligible subjects. The target population was elderly ( $\geq 65$ years old) Taiwanese nationals, who were residing in private residences in Taiwan. For the purpose of this survey, Taiwan was divided into a total of thirteen strata according to geographical locations. A total of thirty-nine city districts or townships were chosen from the thirteen strata using probability proportional to size sampling. From each of the above townships or city districts, two villages (or street blocks) were chosen, resulting in a total of seventy-eight villages or street blocks. The survey comprised of two parts: a household interview and a health examination. A total of 3509 elderly persons were contacted for the household interview and 1937 persons completed the interviews, resulting in a response rate of $55 \cdot 2 \%$. A total of 4606 elderly persons were invited to attend the health examination, and among these, 2432 persons completed the health examinations, resulting in a response rate of
$52 \cdot 8 \%$. A total of 1568 persons had both interview and health examination data. All participants provided written informed consent.

The original study from which the information was used in the present study had ethical approval from the Institutional Review Board of the Academia Sinica, Taiwan.

Female respondents had a slightly lower proportion of individuals who were $\geq 75$ years old than female nonrespondents, but there was no difference in educational levels or ancestral origins, whereas male respondents had fewer Fukienese and Mainlanders and higher Hakka and aboriginal people, but there was no difference in age or education compared with male non-respondents ${ }^{(12)}$. Among them, 456 had missing data and were excluded from the present analysis.

\section{Variables}

Vegetarians were identified from the respondents' responses to three household interview questions. The first question was: 'are you eating a vegetarian diet?' Respondents who selected 'yes' as the answer to this question were referred to as 'vegetarians'. Because some of the Taiwanese eat vegetarian diets $2 \mathrm{~d}$ /month (the first and the fifteenth days of the lunar month) and some people eat vegetarian diets only for breakfast, those who responded 'yes' on the first question were inquired about two other questions: 'on average, how many days in a month do you eat a vegetarian diet?' and 'how many meals/d do you eat a vegetarian diet?' Those who ate three vegetarian meals/ $\mathrm{d}$ and $30 \mathrm{~d}$ a month were defined as 'consistent vegetarians', whereas those who ate at least thirty vegetarian meals a month but less than ninety meals were referred to as 'part-time vegetarians'. Consequently, fortyone individuals who ate 1-29 vegetarian meals/month were excluded from the present analysis, resulting in a final sample of 1071 persons.

One question inquiring about the type of vegetarian diets (vegan, lacto-vegetarian, ovo-vegetarian and ovo-lactovegetarian) that the subjects ate was used to define the type of vegetarian diets.

Sociodemographic variables that were analysed in the present study included age (years), sex, marital status, educational level, employment status and monthly income in 1000 NT (New Taiwan dollar; approximately £22).

Anthropometric data included body height $(\mathrm{cm})$, weight $(\mathrm{kg})$, BMI $\left(\mathrm{kg} / \mathrm{m}^{2}\right)$ and waist circumference $(\mathrm{cm})$. Weight was measured using the SECA 707 continuous display electronic scale (SECA Medical Scales and Measuring Systems, Hamburg, Germany) and height was measured using the SECA 220 height rod (SECA Medical Scales and Measuring Systems). BMI was calculated using the formula weight (kg)/ height ${ }^{2}\left(\mathrm{~m}^{2}\right)$. Waist circumference was measured horizontally at the level of the natural waist, which was identified as the level of the hollow moulding of the trunk when the trunk was concaved laterally.

Lifestyle factors included smoking, alcohol consumption and exercise habits. These lifestyle variables were operationally defined according to a published report ${ }^{(14)}$. Lifetime 
consumption of pack years was used to categorise cigarette smoking. One 'pack-year' corresponds to a consumption of twenty cigarettes/d for 1 year. Subjects were categorised into three categories: never smoked ( $<1$ pack-year); past smoker ( $\geq 1$ pack-year); current smoker ( $\geq 1$ pack-year). Past smokers were those who had stopped smoking $\geq 1$ month before the interview. Alcohol consumption was defined as the weekly consumption of beer, wine and hard liquor converted to grams of alcohol. Alcohol consumption was divided into two categories: no consumption and consumption of alcohol ( $\geq 8 \mathrm{~g} /$ week). Exercise was defined as a significant physical activity that was performed for at least $30 \mathrm{~min} /$ week.

$\mathrm{BP}$ measurements included systolic BP and diastolic BP. BP was measured at the right arm after the subject had rested for at least $5 \mathrm{~min}$, using the Omega 1400 Non-invasive BP Monitor (Invivo Research, Inc., Orlando, FL, USA) and cuffs of appropriate sizes by well-trained personnel. The subject's arm was placed at the heart level. A total of three measurements were taken from each subject. If the second and third measurements differed by more than $10 \mathrm{mmHg}$, a fourth measurement was taken. Systolic BP was defined as the average of three or four systolic BP readings. Diastolic BP was defined as the average of three or four diastolic BP readings.

Metabolic risk profile, including fasting blood glucose, total cholesterol, LDL-cholesterol, HDL-cholesterol, TAG, total cholesterol:HDL-cholesterol, and LDL-cholesterol:HDL-cholesterol, were also analysed.

Nutrient intake was examined using a $24 \mathrm{~h}$ dietary recall, which included an individual recall of types and amounts of foods consumed within $24 \mathrm{~h}$ before the interview, and a cooking method recall by the household cook. Flash cards for oils and spices added to the dishes, and food piece models of twelve Chinese food items and abstract models of size and shapes were used to estimate portion size. The interviewers cross-validated the recall data with other members of the household whenever possible, to ensure the accuracy of the nutrient intake reported by the elderly ${ }^{(13)}$. Nutrient intakes that were analysed included macronutrients (protein, carbohydrates and fat) - for the percentage of energy from protein, carbohydrates and fat - SFA, PUFA, micronutrients (Na, K, Ca and $\mathrm{Mg}$ ), cholesterol and fibre (dietary fibre and crude fibre).

Hypertension was defined using the Joint National Committee on Prevention, Detection, Evaluation and Treatment of High Blood Pressure (JNC VII) ${ }^{(15)}$ cut-off point of $140 \mathrm{mmHg}$ and above for systolic BP and/or $90 \mathrm{mmHg}$ and above for diastolic BP, and also if the subject was on antihypertensive medication.

The MS was defined according to the National Cholesterol Education Program Adult Treatment Panel III criteria(16), with modified Asian cut-offs for waist circumferences ${ }^{(17)}$ and a modified cut-off for fasting glucose $^{(18)}$ as follows: (1) abdominal obesity (i.e. waist circumference $\geq 90 \mathrm{~cm}$ in men and $\geq 80 \mathrm{~cm}$ in women), (2) hypertriacylglycerolaemia (i.e. $\geq 1500 \mathrm{mg} / \mathrm{l}$ ), (3) low HDL-cholesterol (i.e. $<400 \mathrm{mg} / \mathrm{l}$ in men and $<500 \mathrm{mg} / \mathrm{l}$ in women), (4) high BP (i.e. $\geq 130$ / $\geq 85 \mathrm{mmHg}$ ) or treatment of previously diagnosed hypertension and (5) high fasting glucose (i.e. $\geq 1000 \mathrm{mg} / \mathrm{l}$ ) or treatment of previously diagnosed type 2 diabetes. Individuals who had any three of the above components of the MS were defined as individuals with the MS.

\section{Statistical analysis}

Statistical analyses were performed using the Statistical Package for the Social Sciences, version 16.0 (SPSS, Inc., Chicago, IL, USA). Continuous variables are presented as medians and 25 th -75 th percentiles. Categorical variables are presented as frequencies. To reduce the effect that under-reporting of energy might have on estimates of nutrient intakes ${ }^{(19)}$, the energy-adjusted amounts of macro- and micronutrient intakes were used. To this end, the residual method using regression analysis was used ${ }^{(20)}$. Nutrients and energy were log-transformed before tested by regression. Energy-adjusted nutrient intake was calculated as $a+b$, where $a$ is the residual for a subject from the regression model with nutrient intake as the dependent variable and total energy intake as the independent variable, and $b$ is the expected nutrient intake for a person with mean energy intake ${ }^{(21)}$.

The differences in sample characteristics between vegetarians and omnivores were compared using the $\chi^{2}$ test, Fisher's exact test, independent $t$ test and Mann-Whitney $U$ test. Intakes of nutrients as well as metabolic profiles between diet groups were compared. Because data were not normally distributed (Kolmogorov-Smirnov test: $P<0.05$ ), comparisons of nutrients between groups were thus examined by the generalised linear model (GLM). Sex was adjusted in all GLM models. Pairwise comparisons of the estimated marginal means were made, and a $P$ value $<0.05$ was considered as statistically significant. The Bonferroni method was used to adjust the observed significance levels for the fact that multiple contrasts were being tested.

Multivariable logistic regression analysis was performed to examine significant markers of vegetarian status. Logistic regression was used to examine the risk (OR) of hypertension and the MS, and associated 95\% CI in vegetarians compared with omnivores. Multivariable logistic regression modelling was used to adjust all risk estimates for covariates. The significance level was set at $P<0 \cdot 05$.

\section{Results}

Of the 1071 respondents, $802(74.9 \%)$ were omnivores and $269(25 \cdot 1 \%)$ were vegetarians, including forty-one (3.8\%) consistent vegetarians and $228(21.3 \%)$ part-time vegetarians. Among men, only $8 \cdot 1 \%$ were vegetarians, whereas $41.1 \%$ of the women were vegetarians. Of the 269 vegetarians, eightythree (30.9\%) persons were vegans and $186(69 \cdot 1 \%)$ persons were ovo-lactovegetarians $(n 7)$, lacto-vegetarians $(n$ 122) or ovo-lacto-vegetarians ( $n$ 57). Because the numbers of subjects who adopted an ovo-vegetarian or an ovo-lacto-vegetarian diet were small, the above-mentioned three types of vegetarian diets were collapsed into one category (ovo- or lacto-vegetarians).

In terms of the sex distribution between groups, $40 \cdot 5 \%$ of the omnivores were female, whereas $84.4 \%$ of the vegetarians were female $(P<0 \cdot 001)$. As can be seen in Table 1 , among the 
Table 1. Distribution of sample characteristics according to the type of diets consumed and sex (Median values and 25 th-75th percentiles)

\begin{tabular}{|c|c|c|c|c|c|c|c|c|c|c|}
\hline & \multicolumn{5}{|c|}{ Men } & \multicolumn{5}{|c|}{ Women } \\
\hline & \multicolumn{2}{|c|}{ Omnivores ( $n$ 477) } & \multicolumn{2}{|c|}{ Vegetarians ( $n$ 42) } & \multirow[b]{2}{*}{$P$} & \multicolumn{2}{|c|}{ Omnivores (n 325) } & \multicolumn{2}{|c|}{ Vegetarians ( $n$ 227) } & \multirow[b]{2}{*}{$P$} \\
\hline & Median & $\begin{array}{l}\text { 25th-75th } \\
\text { percentiles }\end{array}$ & Median & $\begin{array}{l}\text { 25th-75th } \\
\text { percentiles }\end{array}$ & & Median & $\begin{array}{l}\text { 25th-75th } \\
\text { percentiles }\end{array}$ & Median & $\begin{array}{l}\text { 25th-75th } \\
\text { percentiles }\end{array}$ & \\
\hline Age (years) & 71 & $68-75$ & 72 & $67-76 \cdot 5$ & $0.775^{*}$ & 71 & $67-75$ & 71 & $67-76$ & $0.269^{*}$ \\
\hline $\mathrm{BMI}\left(\mathrm{kg} / \mathrm{m}^{2}\right)$ & 23.3 & $21 \cdot 2-26$ & $22 \cdot 9$ & $21 \cdot 3-25 \cdot 5$ & $0.777 \dagger$ & $24 \cdot 2$ & $21 \cdot 5-26$ & $24 \cdot 1$ & $21 \cdot 3-27$ & $0.276 \dagger$ \\
\hline $\begin{array}{l}\text { Systolic pressure } \\
(\mathrm{mmHg})\end{array}$ & $132 \cdot 3$ & $119 \cdot 3-146 \cdot 4$ & $129 \cdot 3$ & $117 \cdot 4-145 \cdot 9$ & $0.761 \dagger$ & 136 & $121 \cdot 9-153 \cdot 3$ & $139 \cdot 5$ & $125-156$ & $0.083 \dagger$ \\
\hline $\begin{array}{l}\text { Diastolic pressure } \\
\qquad(\mathrm{mmHg})\end{array}$ & 76.5 & $69 \cdot 4-84 \cdot 1$ & $75 \cdot 2$ & $67 \cdot 9-79 \cdot 8$ & $0.122 \dagger$ & $75 \cdot 7$ & $67 \cdot 4-82$ & 75 & $67 \cdot 7-81 \cdot 5$ & $0.834^{*}$ \\
\hline Waist $(\mathrm{cm})$ & $86 \cdot 2$ & $79 \cdot 2-92 \cdot 6$ & $87 \cdot 2$ & $80 \cdot 2-91 \cdot 3$ & $0.806 \dagger$ & 81.5 & $75 \cdot 4-88.5$ & $82 \cdot 3$ & $74 \cdot 6-89 \cdot 6$ & $0.177 \dagger$ \\
\hline \multicolumn{11}{|l|}{ Yes } \\
\hline$n$ & & 446 & & 42 & & & 322 & & 226 & \\
\hline$\%$ & & 93.5 & & 100 & & & $99 \cdot 1$ & & $99 \cdot 6$ & \\
\hline \multicolumn{11}{|l|}{ No } \\
\hline$n$ & & 31 & & 0 & & & 3 & & 1 & \\
\hline$\%$ & & 6.5 & & 0 & & & 0.9 & & 0.4 & \\
\hline Education $\ddagger$ & & & & & 1.000 & & & & & 0.007 \\
\hline \multicolumn{11}{|l|}{ High school and below } \\
\hline$n$ & & 418 & & 37 & & & 315 & & 227 & \\
\hline$\%$ & & $87 \cdot 6$ & & $88 \cdot 1$ & & & 96.9 & & 100 & \\
\hline \multicolumn{11}{|l|}{ College and above } \\
\hline$n$ & & 59 & & 5 & & & 10 & & 0 & \\
\hline$\%$ & & $12 \cdot 4$ & & 11.9 & & & $3 \cdot 1$ & & 0 & \\
\hline $\begin{array}{l}\text { Monthly income } \\
(1000 \mathrm{NT}) \ddagger\end{array}$ & & & & & 1.000 & & & & & $0 \cdot 112$ \\
\hline \multicolumn{11}{|l|}{ Below 20} \\
\hline$n$ & & 406 & & 36 & & & 312 & & 224 & \\
\hline$\%$ & & $85 \cdot 1$ & & 85.7 & & & 96 & & 98.7 & \\
\hline \multicolumn{11}{|l|}{ Above 20} \\
\hline$n$ & & 71 & & 6 & & & 13 & & 3 & \\
\hline$\%$ & & 14.9 & & $14 \cdot 3$ & & & 4 & & 1.3 & \\
\hline Employment‡ & & & & & 0.364 & & & & & 0.539 \\
\hline Yes & & & & & & & & & & \\
\hline$n$ & & 61 & & 8 & & & 21 & & 11 & \\
\hline$\%$ & & $12 \cdot 8$ & & 19 & & & $6 \cdot 5$ & & 4.8 & \\
\hline No & & & & & & & & & & \\
\hline$n$ & & 416 & & 34 & & & 304 & & 216 & \\
\hline$\%$ & & $87 \cdot 2$ & & 81 & & & 93.5 & & $95 \cdot 2$ & \\
\hline Smoking groupł & & & & & 0.317 & & & & & 0.004 \\
\hline Current smoker & & & & & & & & & & \\
\hline$n$ & & 180 & & 11 & & & 17 & & 4 & \\
\hline$\%$ & & $37 \cdot 7$ & & $26 \cdot 2$ & & & $5 \cdot 2$ & & 1.8 & \\
\hline Non-smoker & & & & & & & & & & \\
\hline$n$ & & 180 & & 18 & & & 299 & & 223 & \\
\hline$\%$ & & $37 \cdot 7$ & & $42 \cdot 9$ & & & 92 & & $98 \cdot 2$ & \\
\hline Past smoker & & & & & & & & & & \\
\hline$n$ & & 117 & & 13 & & & 9 & & 0 & \\
\hline$\%$ & & 24.5 & & 31 & & & $2 \cdot 8$ & & 0 & \\
\hline Exercise group $\ddagger$ & & & & & 0.605 & & & & & $<0.001$ \\
\hline Yes & & & & & & & & & & \\
\hline$n$ & & 258 & & 25 & & & 134 & & 129 & \\
\hline$\%$ & & $54 \cdot 1$ & & 59.5 & & & $41 \cdot 2$ & & $56 \cdot 8$ & \\
\hline No & & & & & & & & & & \\
\hline$n$ & & 219 & & 17 & & & 191 & & 98 & \\
\hline$\%$ & & $45 \cdot 9$ & & 40.5 & & & 58.8 & & $43 \cdot 2$ & \\
\hline Alcohol consumptionł & & & & & 0.667 & & & & & 0.284 \\
\hline Yes & & & & & & & & & & \\
\hline$n$ & & 99 & & 7 & & & 12 & & 4 & \\
\hline$\%$ & & $20 \cdot 8$ & & $16 \cdot 7$ & & & 3.7 & & $1 \cdot 8$ & \\
\hline No & & & & & & & & & & \\
\hline$n$ & & 378 & & 35 & & & 313 & & 223 & \\
\hline$\%$ & & $79 \cdot 2$ & & 83.3 & & & $96 \cdot 3$ & & $98 \cdot 2$ & \\
\hline
\end{tabular}

NT, New Taiwan dollars; 1000 NT = approximately £22.

* Group comparison by the Mann-Whitney $U$ test.

$\dagger$ Group comparison by the independent $t$ test.

$\ddagger$ Group comparison by the $\chi^{2}$ test. 
Table 2. Nutrient intakes in subjects according to the type of diets consumed* (Median values and 25th-75th percentiles)

\begin{tabular}{|c|c|c|c|c|c|}
\hline & \multicolumn{2}{|c|}{ Omnivores ( $n$ 802) } & \multicolumn{2}{|c|}{ Vegetarians ( $n$ 269) } & \multirow[b]{2}{*}{$P \dagger$} \\
\hline & Median & 25th-75th percentiles & Median & 25th-75th percentiles & \\
\hline \multicolumn{6}{|l|}{ Nutrient intake } \\
\hline Energy $(\mathrm{kJ} / \mathrm{d})$ & $6548 \cdot 3$ & $4807 \cdot 4-9154 \cdot 8$ & $5423 \cdot 6$ & $3928 \cdot 9-7282 \cdot 7$ & $<0.001$ \\
\hline Carbohydrates (\%) & $56 \cdot 8$ & $46 \cdot 4-65 \cdot 5$ & $57 \cdot 8$ & $48 \cdot 5-66 \cdot 4$ & 0.224 \\
\hline Protein (\%) & $16 \cdot 2$ & $13 \cdot 4-19 \cdot 8$ & $16 \cdot 2$ & $12 \cdot 8-20 \cdot 0$ & 0.543 \\
\hline Fat (\%) & $25 \cdot 4$ & $17 \cdot 4-35 \cdot 1$ & $24 \cdot 6$ & $16 \cdot 6-33 \cdot 7$ & 0.092 \\
\hline Fat as SFA (\%) & $28 \cdot 8$ & $23.5-33.9$ & $27 \cdot 2$ & $21 \cdot 6-32 \cdot 9$ & 1.000 \\
\hline Fat as PUFA (\%) & $29 \cdot 6$ & $22 \cdot 4-38.9$ & $32 \cdot 9$ & $24 \cdot 2-41 \cdot 9$ & 0.022 \\
\hline $\mathrm{Na}(\mathrm{mg} / \mathrm{d})$ & 3867.5 & $2534-6009 \cdot 9$ & $3761 \cdot 0$ & $2489 \cdot 5-6044 \cdot 7$ & 0.509 \\
\hline $\mathrm{K}(\mathrm{mg} / \mathrm{d})$ & $2074 \cdot 2$ & $1518 \cdot 9-2918.9$ & $2168 \cdot 8$ & $1609 \cdot 1-3187 \cdot 4$ & 0.109 \\
\hline $\mathrm{Ca}(\mathrm{mg} / \mathrm{d})$ & 439.4 & $238 \cdot 1-853 \cdot 8$ & $588 \cdot 3$ & $305 \cdot 1-1088 \cdot 5$ & $<0.001$ \\
\hline $\mathrm{Mg}(\mathrm{mg} / \mathrm{d})$ & $206 \cdot 9$ & $162-275 \cdot 7$ & $230 \cdot 4$ & $163 \cdot 8-300 \cdot 6$ & $0 \cdot 106$ \\
\hline Cholesterol (mg/d) & 174.6 & $102 \cdot 6-289 \cdot 9$ & $142 \cdot 1$ & $70 \cdot 4-245 \cdot 9$ & 0.002 \\
\hline \multicolumn{6}{|l|}{ Fibre (g/d) } \\
\hline Dietary fibre & $16 \cdot 7$ & $11 \cdot 2-24.7$ & $18 \cdot 8$ & $12 \cdot 5-26 \cdot 1$ & 0.103 \\
\hline Crude fibre & $3 \cdot 8$ & $2 \cdot 5-5 \cdot 7$ & 4.1 & $2 \cdot 8-6 \cdot 1$ & 0.041 \\
\hline
\end{tabular}

*Test by the generalised linear model. † Sex-adjusted.

male participants, omnivores and vegetarians were not significantly different in any one of the sample characteristics. In the female participants, vegetarians had a significantly lower level of education $(P=0.007)$, a lower smoking rate $(P=0.004)$ and a higher percentage of persons who regularly exercised $(P<0 \cdot 001)$ compared with omnivores.

Multivariable logistic regression analysis revealed that systolic pressure (OR 1.01, 95\% CI 1, 1.02, P=0.038), female sex (OR 5.02, 95\% CI 3.11, 8.1, $P<0.001$ ), smoking status $(P=0.034$; current smoker (OR $0.45,95 \%$ CI $0.24,0.85$, $P=0 \cdot 014)$ ) and regular exercise (OR 1.87, 95\% CI 1.37, 2.56, $P<0.001)$ were independently and significantly associated with vegetarian status, but not with age, BMI, waist circumference, diastolic pressure, marital status, education, income, alcohol consumption and employment status (all $P>0.05$ ).

In terms of sex-adjusted comparisons of macro- and micronutrient intakes between vegetarians and omnivores, GLM analyses revealed that vegetarians consumed significantly lower daily total energy $(P<0.001)$ and cholesterol $(P=0.002)$, a higher percentage of fat as PUFA $(P=0.022)$, $\mathrm{Ca}(P<0.001)$ and crude fibres $(P=0.041)$ than omnivores (Table 2). The percentage of total energy from each key nutrient was not significantly different between vegetarians and omnivores (all $P>0.05$; Table 2).

As indicated by the tests for trend, in the male sample, daily total energy $(P=0.031)$ and cholesterol intake $(P=0.005)$ decreased and intakes of $\mathrm{Ca}(P=0 \cdot 011), \mathrm{Mg}(P=0 \cdot 022)$, dietary fibres $(P=0.026)$ and crude fibres $(P=0.036)$ increased as the frequency of vegetarian diets increased (Table 3 ). In the female sample, daily total energy $(P=0.014)$ and cholesterol intake $(P=0.004)$ decreased and intakes of fat as PUFA $(P=0.007)$ and $\mathrm{Ca}(P=0.012)$ increased, as the frequency of vegetarian diets increased (Table 4 ).

The two types of vegetarian diets were then compared with non-vegetarian diets by means of the GLM. The three diet groups differ significantly in daily total energy intake, percentage of fat as PUFA, $\mathrm{Na}, \mathrm{K}, \mathrm{Ca}, \mathrm{Mg}$, cholesterol and crude fibres (all $P<0.05$; Table 5). Post hoc comparisons revealed that ovoor lacto-vegetarians and vegans consumed significantly lower daily total energy than omnivores $(P=0.005$ and 0.015 , respectively). Vegan diets had a significantly higher percentage of PUFA ( $P=0.002$ and 0.023 , respectively) and higher Na content $(P=0.049$ and 0.021 , respectively) than both ovoor lacto-vegetarian diets and non-vegetarian diets. Ovo- or lacto-vegetarians consumed significantly higher $\mathrm{K}, \mathrm{Ca}, \mathrm{Mg}$ and crude fibres than omnivores and vegans (all $P<0.05$; Table 5). Ovo- or lacto-vegetarians consumed significantly lower cholesterol than omnivores $(P=0 \cdot 027)$.

In terms of the metabolic profile, GLM analyses revealed that vegetarians and omnivores were comparable in all metabolic indicators (all $P>0 \cdot 05$ ). Similarly, all metabolic factors were not significantly different among omnivores, ovo- or lacto-vegetarians and vegans (all $P>0.05$ ). Omnivores, parttime vegetarians and full-time vegetarians were also comparable in all metabolic factors (all $P>0 \cdot 05$ ).

The prevalence rates of hypertension were $54 \cdot 4,58 \cdot 3$ and $56.1 \%$ in omnivores, part-time vegetarians and consistent vegetarians, respectively. The prevalence rates of hypertension for ovo- or lacto-vegetarians and vegans were 57.5 and 59\%, respectively. The likelihood of hypertension was not significantly different between vegetarians and omnivores as examined by unadjusted, sex-adjusted or multivariate-adjusted (sex, smoking and exercise) logistic regression models ( $P=0 \cdot 301$, 0.789 and 0.877 , respectively; Table 6). The likelihood of hypertension was also comparable among consistent vegetarians, part-time vegetarians and omnivores, as examined by unadjusted or sex-adjusted logistic regression models (all $P>0.05$; Table 6). Similarly, the likelihood of hypertension was not significantly different among vegans, ovo- or lactovegetarians and omnivores, as examined by unadjusted or sex-adjusted logistic regression models (all $P>0.05$; Table 6).

The prevalence rates of the MS were 39.4, 52.6 and $43.9 \%$ in omnivores, part-time vegetarians and consistent vegetarians, respectively. The prevalence rates of the MS for ovo- or 
Table 3. Intakes of nutrients among male omnivores, part-time vegetarians and consistent vegetarians (Median values and 25th-75th percentiles)

\begin{tabular}{|c|c|c|c|c|c|c|c|}
\hline & \multicolumn{2}{|c|}{ Omnivores ( $n$ 477) } & \multicolumn{2}{|c|}{ Part-time vegetarians ( $n$ 32) } & \multicolumn{2}{|c|}{ Consistent vegetarians $(n 10)$} & \multirow[b]{2}{*}{$P^{*}$} \\
\hline & Median & 25th-75th percentiles & Median & 25th-75th percentiles & Median & 25th-75th percentiles & \\
\hline \multicolumn{8}{|l|}{ Nutrient intake } \\
\hline Energy $(\mathrm{kJ} / \mathrm{d})$ & $7207 \cdot 7$ & $5361 \cdot 4-9529 \cdot 2$ & 5979.5 & $4909 \cdot 8-7934$ & $6024 \cdot 7$ & $5373-7458 \cdot 3$ & 0.031 \\
\hline Carbohydrates (\%) & $57 \cdot 1$ & $47-65.5$ & $56 \cdot 5$ & $47 \cdot 1-65 \cdot 4$ & 68 & $59.5-74.4$ & 0.053 \\
\hline Protein (\%) & $16 \cdot 3$ & $13 \cdot 4-20 \cdot 1$ & $16 \cdot 3$ & $13 \cdot 9-21 \cdot 2$ & $16 \cdot 6$ & $11.8-19.9$ & 0.753 \\
\hline Fat $(\%)$ & 24.9 & $17 \cdot 6-34.6$ & $25 \cdot 9$ & $17 \cdot 4-34 \cdot 7$ & $16 \cdot 6$ & $11 \cdot 9-21 \cdot 2$ & 0.144 \\
\hline Fat as SFA (\%) & $28 \cdot 8$ & $23 \cdot 7-34$ & $28 \cdot 3$ & $21 \cdot 8-33.5$ & $19 \cdot 7$ & $14-28$ & 0.100 \\
\hline Fat as PUFA (\%) & 29.8 & $22 \cdot 6-39 \cdot 2$ & 33.7 & $20 \cdot 8-39.9$ & $37 \cdot 3$ & $16 \cdot 9-44 \cdot 7$ & 0.592 \\
\hline $\mathrm{Na}(\mathrm{mg} / \mathrm{d})$ & 4033.4 & $2696 \cdot 5-6194 \cdot 2$ & 3855 & $2858 \cdot 6-6765 \cdot 3$ & $3007 \cdot 2$ & $1610 \cdot 4-4603 \cdot 9$ & 0.616 \\
\hline $\mathrm{K}(\mathrm{mg} / \mathrm{d})$ & $2005 \cdot 9$ & $1476 \cdot 4-2814 \cdot 3$ & $2173 \cdot 3$ & $1635-2992 \cdot 3$ & $2813 \cdot 8$ & $2066 \cdot 1-3414 \cdot 2$ & 0.085 \\
\hline $\mathrm{Ca}(\mathrm{mg} / \mathrm{d})$ & 423.1 & $234 \cdot 1-780 \cdot 2$ & $516 \cdot 8$ & $302 \cdot 3-1049 \cdot 8$ & 745 & $573-875$ & 0.011 \\
\hline$M g(\mathrm{mg} / \mathrm{d})$ & $206 \cdot 7$ & $161 \cdot 8-271 \cdot 2$ & 207.7 & $176 \cdot 7-291 \cdot 4$ & $302 \cdot 2$ & $253 \cdot 3-384$ & 0.022 \\
\hline Cholesterol (mg/d) & $182 \cdot 3$ & $108 \cdot 5-302 \cdot 4$ & $151 \cdot 8$ & $85 \cdot 3-221 \cdot 8$ & $45 \cdot 4$ & $22 \cdot 6-169 \cdot 7$ & 0.005 \\
\hline \multicolumn{8}{|l|}{ Fibre $(\mathrm{g} / \mathrm{d})$} \\
\hline Dietary fibre & $16 \cdot 6$ & $11-24 \cdot 1$ & $20 \cdot 8$ & $10 \cdot 9-24.5$ & $29 \cdot 1$ & $23 \cdot 1-35$ & 0.026 \\
\hline Crude fibre & $3 \cdot 7$ & $2 \cdot 4-5 \cdot 5$ & 4.4 & $2 \cdot 2-6 \cdot 7$ & $6 \cdot 4$ & $4 \cdot 8-8$ & 0.036 \\
\hline
\end{tabular}

*Tests for trend.

lacto-vegetarians and vegans were 48.4 and $57.8 \%$, respectively. The unadjusted OR of the MS for vegetarians was 1.62 (CI $1 \cdot 23,2 \cdot 14, P=0 \cdot 001$ ) compared with omnivores (Table 7). After controlling for sex alone, or controlling for sex, smoking group and exercise group, being vegetarian did not have a significant impact on the incidence of the MS $(P=0.426$ and 0.491; Table 7). Similarly, the likelihood of the MS was also comparable among consistent vegetarians, part-time vegetarians and omnivores after adjusting for sex $(P=0.746$ and 0.311; Table 7). The likelihood of the MS was significantly higher for both vegans (OR $2 \cdot 11$, CI $1 \cdot 33,3 \cdot 34, P=0 \cdot 001$ ) and Ovo- or lacto-vegetarians (OR 1.44, CI 1.05, 1.99, $P=0.025)$ compared with omnivores, as examined by unadjusted logistic regression. However, the likelihood of the MS was not significantly different among the three types of diets for both vegans and ovo- or lacto-vegetarians, after adjusting for sex ( $P=0 \cdot 115$ and 0.962, respectively; Table 7).

\section{Discussion}

Nearly one-quarter of the elderly in Taiwan were either parttime or consistent vegetarians. Approximately 3.8\% of the Taiwanese elderly population described themselves as a consistent follower of a vegetarian diet. Approximately two-thirds of the vegetarians adopted ovo- or lacto-vegetarian diets. There was a female predominance in these vegetarians. Female sex, non-smoking habit and regular exercise were factors independently associated with vegetarian status among Taiwanese elderly persons.

Dietary factors have been implicated to play a prominent role in the pathogenesis of elevated $\mathrm{BP}^{(22)}$. Of note, in the present sample, over $50 \%$ of the elderly persons had a BP level that met the definition of hypertension. Contradicting previous findings from research conducted in Western populations, we found that being on vegetarian diets did not lower the odds of JNC VII-defined hypertension among Taiwanese

Table 4. Intakes of nutrients among female omnivores, part-time vegetarians and consistent vegetarians (Median values and 25th-75th percentiles)

\begin{tabular}{|c|c|c|c|c|c|c|c|}
\hline & \multicolumn{2}{|c|}{ Omnivores ( $n$ 325) } & \multicolumn{2}{|c|}{ Part-time vegetarians ( $n$ 196) } & \multicolumn{2}{|c|}{ Consistent vegetarians ( $n$ 31) } & \multirow[b]{2}{*}{$P^{*}$} \\
\hline & Median & 25th-75th percentiles & Median & 25th-75th percentiles & Median & 25th-75th percentiles & \\
\hline \multicolumn{8}{|l|}{ Nutrient intake } \\
\hline Energy $(\mathrm{kJ} / \mathrm{d})$ & 5941 & $4041 \cdot 1-7887 \cdot 5$ & 5326 & $3756 \cdot 1-7418$ & 4771 & $3371 \cdot 4-6479.4$ & 0.014 \\
\hline Carbohydrates (\%) & 56.5 & $45 \cdot 1-65 \cdot 5$ & $57 \cdot 4$ & $47 \cdot 3-66 \cdot 2$ & $60 \cdot 9$ & $52 \cdot 7-69 \cdot 8$ & 0.145 \\
\hline Protein (\%) & 16 & $13 \cdot 4-19 \cdot 5$ & $16 \cdot 4$ & $13 \cdot 1-20 \cdot 3$ & $15 \cdot 7$ & $11 \cdot 4-18 \cdot 6$ & 0.928 \\
\hline Fat (\%) & $26 \cdot 4$ & $17 \cdot 1-36 \cdot 4$ & $25 \cdot 1$ & $17 \cdot 6-34 \cdot 7$ & 21.3 & $14 \cdot 6-29 \cdot 2$ & 0.192 \\
\hline Fat as SFA (\%) & $29 \cdot 1$ & $22 \cdot 6-33 \cdot 7$ & 28.4 & $22 \cdot 1-33 \cdot 4$ & $22 \cdot 3$ & $18 \cdot 3-26 \cdot 6$ & 0.113 \\
\hline Fat as PUFA (\%) & $29 \cdot 3$ & $21 \cdot 7-38 \cdot 8$ & $32 \cdot 1$ & $24.3-41.5$ & $38 \cdot 3$ & $25-47 \cdot 2$ & 0.007 \\
\hline $\mathrm{Na}(\mathrm{mg} / \mathrm{d})$ & $3718 \cdot 8$ & $2449 \cdot 3-5861 \cdot 1$ & 3800.9 & $2467 \cdot 3-5941 \cdot 1$ & $3311 \cdot 1$ & $2651 \cdot 2-5948 \cdot 8$ & 0.719 \\
\hline $\mathrm{K}(\mathrm{mg} / \mathrm{d})$ & $2123 \cdot 1$ & $1555-3019 \cdot 5$ & $2125 \cdot 5$ & $1543 \cdot 3-3145 \cdot 8$ & $2422 \cdot 7$ & $1565 \cdot 7-3747 \cdot 1$ & 0.293 \\
\hline $\mathrm{Ca}(\mathrm{mg} / \mathrm{d})$ & 489 & $247.5-953.9$ & 576.6 & $264 \cdot 2-1085 \cdot 6$ & $749 \cdot 2$ & $477.5-1458.5$ & 0.012 \\
\hline $\mathrm{Mg}(\mathrm{mg} / \mathrm{d})$ & 208 & $162 \cdot 1-280 \cdot 4$ & 223.8 & $157 \cdot 2-287 \cdot 1$ & $257 \cdot 1$ & $201 \cdot 2-360 \cdot 2$ & 0.091 \\
\hline Cholesterol (mg/d) & $163 \cdot 6$ & $96 \cdot 7-267 \cdot 7$ & $148 \cdot 3$ & $85 \cdot 6-259 \cdot 6$ & 24 & $0-152 \cdot 2$ & 0.004 \\
\hline \multicolumn{8}{|l|}{ Fibre $(\mathrm{g} / \mathrm{d})$} \\
\hline Dietary fibre & $16 \cdot 8$ & $11 \cdot 3-25 \cdot 4$ & $17 \cdot 3$ & $11 \cdot 7-24 \cdot 3$ & 25.4 & $16 \cdot 3-33 \cdot 8$ & 0.178 \\
\hline Crude fibre & 3.8 & $2 \cdot 5-6 \cdot 0$ & 4 & $2 \cdot 7-5 \cdot 8$ & $5 \cdot 3$ & $3.2-7.5$ & 0.059 \\
\hline
\end{tabular}

* Tests for trend. 
Table 5. Intakes of nutrients among omnivores, ovo-lacto-vegetarians and vegans* (Median values and 25th-75th percentiles)

\begin{tabular}{|c|c|c|c|c|c|c|c|c|c|c|}
\hline & \multicolumn{2}{|c|}{ Omnivores ( $n$ 802) } & \multicolumn{2}{|c|}{ Ovo-lacto-vegetarians ( $n$ 186) } & \multicolumn{2}{|c|}{ Vegans ( $n$ 83) } & \multirow[b]{2}{*}{$P \dagger$} & \multirow[b]{2}{*}{$P \ddagger$} & \multirow[b]{2}{*}{$P \S$} & \multirow[b]{2}{*}{$P \|$} \\
\hline & Median & 25th-75th percentiles & Median & 25th-75th percentiles & Median & 25th-75th percentiles & & & & \\
\hline \multicolumn{11}{|l|}{ Nutrient intake } \\
\hline Energy $(\mathrm{kJ} / \mathrm{d})$ & $6548 \cdot 3$ & $4807 \cdot 4-9154.8$ & 5452.4 & $3915 \cdot 6-7437.3$ & $5407 \cdot 3$ & $3918 \cdot 3-7134.4$ & 0.001 & 0.005 & 0.015 & 1.000 \\
\hline Carbohydrates (\%) & $56 \cdot 8$ & $46 \cdot 4-65 \cdot 5$ & $57 \cdot 3$ & $47 \cdot 7-66 \cdot 2$ & $59 \cdot 3$ & $51-68 \cdot 3$ & 0.229 & & & \\
\hline Protein $(\%)$ & $16 \cdot 2$ & $13 \cdot 4-19 \cdot 8$ & $16 \cdot 4$ & $13 \cdot 6-20 \cdot 2$ & $15 \cdot 3$ & $11 \cdot 6-19 \cdot 7$ & 0.773 & & & \\
\hline Fat $(\%)$ & 25.4 & $17 \cdot 4-35 \cdot 1$ & $25 \cdot 3$ & $16 \cdot 6-34.9$ & 23 & $16 \cdot 6-30 \cdot 3$ & 0.101 & & & \\
\hline Fat as SFA (\%) & $28 \cdot 8$ & $23.5-33.9$ & 28.4 & $21.7-34.9$ & $26 \cdot 1$ & $20 \cdot 7-30.9$ & 0.469 & & & \\
\hline Fat as PUFA (\%) & $29 \cdot 6$ & $22 \cdot 4-38.9$ & 31.4 & $22 \cdot 7-41 \cdot 2$ & $35 \cdot 7$ & $28 \cdot 3-45 \cdot 3$ & 0.003 & 1.000 & 0.002 & 0.023 \\
\hline $\mathrm{Na}(\mathrm{mg} / \mathrm{d})$ & 3867.5 & $2534-6009 \cdot 9$ & 3579.8 & $2307 \cdot 8-5665 \cdot 3$ & $4124 \cdot 4$ & $2924 \cdot 3-6832 \cdot 4$ & 0.025 & 1.000 & 0.049 & 0.021 \\
\hline $\mathrm{K}(\mathrm{mg} / \mathrm{d})$ & $2074 \cdot 2$ & $1518 \cdot 9-2918 \cdot 9$ & $2361 \cdot 8$ & $1850 \cdot 7-3279 \cdot 2$ & 1727.5 & $1292 \cdot 7-2384 \cdot 3$ & 0.001 & 0.010 & 0.180 & 0.001 \\
\hline $\mathrm{Ca}(\mathrm{mg} / \mathrm{d})$ & 439.4 & $238 \cdot 1-853 \cdot 8$ & 694.8 & $409 \cdot 7-1186 \cdot 8$ & 305.4 & $200 \cdot 5-649.8$ & $<0.001$ & $<0.001$ & 0.481 & $<0.001$ \\
\hline$M g(m g / d)$ & $206 \cdot 9$ & $162-275 \cdot 7$ & $249 \cdot 1$ & $183 \cdot 7-311.5$ & 191 & $148 \cdot 7-266 \cdot 4$ & 0.003 & 0.017 & 0.465 & 0.005 \\
\hline Cholesterol (mg/d) & $174 \cdot 6$ & $102 \cdot 6-289 \cdot 9$ & $151 \cdot 8$ & $81-259 \cdot 2$ & 121.9 & $35 \cdot 5-232 \cdot 1$ & 0.008 & 0.027 & 0.063 & 1.000 \\
\hline \multicolumn{11}{|l|}{ Fibre $(g / d)$} \\
\hline Dietary fibre & $16 \cdot 7$ & $11.2-24.7$ & $19 \cdot 6$ & $13 \cdot 1-27 \cdot 9$ & $16 \cdot 7$ & $11 \cdot 7-22 \cdot 7$ & 0.252 & & & \\
\hline Crude fibre & 3.8 & $2 \cdot 5-5 \cdot 7$ & $4 \cdot 3$ & $3-6 \cdot 7$ & 3.9 & $2 \cdot 4-5.4$ & 0.003 & 0.008 & 0.918 & 0.008 \\
\hline
\end{tabular}

*Test by the generalised linear model.

† Sex adjusted.

$\ddagger$ Post hoc comparison between omnivores and ovo-lacto-vegetarians.

$\S$ Post hoc comparison between omnivores and vegans.

| Post hoc comparison between ovo-lacto-vegetarians and vegans. 
Table 6. Vegetarian habit in predicting hypertension* (Odds ratios and $95 \%$ confidence intervals)

\begin{tabular}{|c|c|c|c|}
\hline & OR & $95 \% \mathrm{Cl}$ & $P$ \\
\hline \multicolumn{4}{|l|}{ Vegetarians } \\
\hline Unadjusted & $1 \cdot 16$ & $0.88,1.53$ & 0.301 \\
\hline Sex-adjusted & 1.04 & $0.77,1.41$ & 0.789 \\
\hline Multivariate-adjusted $\dagger$ & 1.02 & $0.76,1.39$ & 0.877 \\
\hline Omnivores & 1 & & \\
\hline \multicolumn{4}{|l|}{ Consistent vegetarians } \\
\hline Unadjusted & 1.07 & $0.57,2.02$ & 0.828 \\
\hline Sex-adjusted & 0.99 & $0.52,1.87$ & 0.965 \\
\hline \multicolumn{4}{|l|}{ Part-time vegetarians } \\
\hline Unadjusted & $1 \cdot 18$ & $0.87,1.58$ & 0.288 \\
\hline Sex-adjusted & 1.05 & $0.76,1.45$ & 0.752 \\
\hline Omnivores & 1 & & \\
\hline \multicolumn{4}{|l|}{ Vegans } \\
\hline Unadjusted & 1.21 & $0.76,1.92$ & 0.416 \\
\hline Sex-adjusted & 1.09 & $0.68,1.74$ & 0.736 \\
\hline \multicolumn{4}{|l|}{ Ovo- or lacto-vegetarians } \\
\hline Unadjusted & 1.14 & $0.82,1.57$ & 0.435 \\
\hline Sex-adjusted & 1.02 & $0.73,1.44$ & 0.893 \\
\hline Omnivores & 1 & & \\
\hline
\end{tabular}

*Test by logistic regression.

† Controlling for sex, smoking group and exercise group.

elderly persons. This result was, however, in accordance with the findings from a previous study of Taiwanese elderly persons ${ }^{(10)}$. Recommended dietary approaches to lower BP include weight loss, reduced salt intake, increased $\mathrm{K}$ intake and moderation of alcohol intake ${ }^{(22)}$. In addition, it has previously been suggested that BMI may in part account for the BP-lowering effect associated with vegetarian diets ${ }^{(2)}$. In the present study, we did not reveal significant differences in daily $\mathrm{Na}$ intakes between vegetarian and non-vegetarian diets nor was BMI significantly different between the diet groups. Surprisingly, vegans had even higher $\mathrm{Na}$ intakes than non-vegetarians. These factors may explain the apparent lack of association between vegetarian dietary habits and hypertension.

The MS is not a disease per se. It represents a constellation of cardiovascular and metabolic risk factors that presumably predispose individuals to CVD and diabetes. Hence, dietary approaches to the MS have been focused on individual risk components. For example, low-fat, low-cholesterol diets, such as the 'therapeutic lifestyle changes' diet recommended by the National Cholesterol Education Program of the US National Institutes of Health ${ }^{(16)}$, have been suggested to lower high blood cholesterol. Plant-based diets also have been shown to exert lipid-lowering effects ${ }^{(23)}$. However, in the present study, we did not find significant differences in the metabolic profile between diet groups. In addition, the prevalence of the MS was slightly higher in vegetarians than in omnivores. Moreover, our findings did not provide evidence to support the beneficial effect of vegetarian diets on lowering the odds of the National Cholesterol Education Program Adult Treatment Panel III-defined MS. Because the present study was cross-sectional in nature, the question of whether vegetarian diets lack beneficial effects for hypertension or the MS remains inconclusive.
In the present study, we examined a representative Taiwanese elderly sample and found that vegetarian diets were not associated with a favourable metabolic profile. These findings were contradictory to those observed in a convenience sample of Taiwanese vegetarians ${ }^{(7)}$, but coincided with those obtained from a group of elderly people in Taiwan in a recent study ${ }^{(11)}$. Interestingly enough, we found that vegetarian status was associated with a healthier lifestyle (e.g. exercising regularly and not smoking). As the information on the duration for eating a vegetarian diet in these subjects was lacking and the study used a cross-sectional design, the direction of influence of vegetarian diets on lifestyle habits remains to be determined.

The features of a vegetarian diet responsible for its beneficial effects, if any, remain to be studied. It has been suggested that cardiovascular benefits of vegetarian diets may be associated with lower dietary saturated fat, cholesterol and animal proteins, and higher dietary fibres ${ }^{(1)}$. In addition, $\mathrm{K}, \mathrm{Ca}, \mathrm{Mg}$ and dietary fibre are beneficial compounds that could result in lower $\mathrm{BP}^{(24)}$. In the present study, vegetarian diets had higher $\mathrm{Ca}$ and fibres compared with non-vegetarian diets. We also found that intakes of beneficial micronutrients such as $\mathrm{Ca}$ or $\mathrm{Mg}$ increased, whereas cholesterol consumption decreased as the frequency of vegetarian diets increased. Between the two vegetarian diets, ovo- or lacto-vegetarian diets contained more beneficial micronutrients, such as $\mathrm{K}$, $\mathrm{Ca}$ and $\mathrm{Mg}$, and higher crude fibres than vegan diets.

The findings of the present study showed that the percentage of dietary carbohydrate consumed by the elderly in Taiwan was relatively higher than those of Western diets but lower than those of developing countries ${ }^{(25)}$. The percentage of energy from carbohydrate was comparable between vegetarian and non-vegetarian diets. An unfavourable effect of dietary carbohydrate intake on lipids has been demonstrated in cross-sectional studies ${ }^{(26,27)}$. Future studies using a

Table 7. Vegetarian habit in predicting the metabolic syndrome* (Odds ratios and $95 \%$ confidence intervals)

\begin{tabular}{llll}
\hline & OR & $95 \% \mathrm{Cl}$ & $P$ \\
\hline Vegetarians & & & \\
$\quad$ Unadjusted & 1.62 & $1.23,2.14$ & 0.001 \\
$\quad$ Sex-adjusted & 1.13 & $0.84,1.53$ & 0.426 \\
$\quad$ Multivariate-adjusted & 1.11 & $0.82,1.51$ & 0.491 \\
Omnivores & 1 & & \\
Consistent vegetarians & & & \\
$\quad$ Unadjusted & 1.20 & $0.64,2.27$ & 0.566 \\
$\quad$ Sex-adjusted & 0.90 & $0.47,1.72$ & 0.746 \\
Part-time vegetarians & & & \\
$\quad$ Unadjusted & 1.71 & $1.27,2.30$ & $<0.001$ \\
$\quad$ Sex-adjusted & 1.18 & $0.86,1.63$ & 0.311 \\
Omnivores & 1 & & \\
Vegans & & & 0.001 \\
$\quad$ Unadjusted & 2.11 & $1.33,3.34$ & 0.115 \\
$\quad$ Sex-adjusted & 1.47 & $0.91,2.36$ & \\
Ovo-lacto-vegetarians & & & 0.025 \\
$\quad$ Unadjusted & 1.44 & $1.05,1.99$ & 0.962 \\
$\quad$ Sex-adjusted & 1.01 & $0.72,1.42$ & \\
Omnivores & 1 & & \\
\hline
\end{tabular}

* Test by logistic regression.

†Controlling for sex, smoking group and exercise group. 
longitudinal or randomised controlled design should explore the effect of dietary carbohydrate on lipid profiles.

Several limitations of the present study must be addressed. First, under-reporting of intake is one of the major threats to the validity of dietary assessment ${ }^{(19,20)}$. Because nutrient intakes were derived from a $24 \mathrm{~h}$ dietary recall in the present study, under-reporting of intake could possibly influence the results and conclusions drawn from the results. Based on data from the Nutrition and Health Survey in Taiwan (1993-6), the average dietary energy consumption was $12294 \mathrm{~kJ} / \mathrm{d}^{(28)}$, which was much higher than the energy intake reported by the elderly in the present study. It is thus likely that energy intake was under-reported in this population. Nevertheless, we used energy-adjusted amounts of macro- and micronutrient intakes instead of the absolute intakes to reduce the effect that under-reporting of energy might have on estimates of nutrient intakes. Second, due to the moderate response rate of the Elderly Nutrition and Health Survey in Taiwan, generalisability of the present study may be limited. Nevertheless, respondents and non-respondents showed only slight differences in ancestral origins in the male sample and age distribution in the female sample.

In conclusion, female sex and regular exercise were independent determinants of vegetarian status among Taiwanese elderly persons. Being on vegetarian diets neither lowered the odds of JNC VII-defined hypertension nor did it lower the likelihood of the National Cholesterol Education Program Adult Treatment Panel III-defined MS among Taiwanese elderly persons. Taiwanese elderly vegetarians consumed lower daily total energy and higher beneficial nutrient compounds such as $\mathrm{K}, \mathrm{Ca}, \mathrm{Mg}$ and fibres than their counterparts. The present study provides insights into the characteristics and nutrient intakes of Taiwanese elderly person who eat a vegetarian diet.

\section{Acknowledgements}

Data analysed in the present study were collected from the research project 'Elderly Nutrition and Health Survey in Taiwan (1999-2000)' sponsored by the Department of Health, Executive Yuan. The present study was carried out by the Institute of Biomedicine Sciences, Academia Sinica, and directed by Dr Wen-Harn Pan. The Center for Survey Research of Academia, Sinica is responsible for the data distribution. The authors appreciate the assistance in providing data by the institutes and individuals aforementioned. The views expressed herein are the authors' own. The study received no specific grant from any funding agency in the public, commercial or not-for-profit sectors. Authors' contributions were as follows: P.-S. T. provided the idea and contributed to the study design, data acquisition, data analysis, data interpretation, manuscript preparation and revision. C.-J. H. was involved in the conception of the idea, study design, data interpretation and manuscript preparation. Y.-C. F. was involved in the data analysis, interpretation, manuscript preparation and revision. J.-F. L. contributed to the data interpretation and manuscript preparation.

\section{References}

1. Craig WJ, Mangels AR \& American Dietetic Association (2009) Position of the American Dietetic Association: vegetarian diets. J Am Diet Assoc 109, 1266-1282.

2. Appleby PN, Davey GK \& Key TJ (2002) Hypertension and blood pressure among meat eaters, fish eaters, vegetarians and vegans in EPIC-Oxford. Public Health Nutr 5, 645-654.

3. Fraser GE (1999) Associations between diet and cancer, ischemic heart disease, and all-cause mortality in non-Hispanic white California Seventh-day Adventists. Am J Clin Nutr 70, 532S-538S.

4. Fraser GE (2009) Vegetarian diets: what do we know of their effects on common chronic diseases? Am J Clin Nutr 89, 1607S-1612S.

5. Tzeng MS, Kao MD, Yeh WT, et al. (1999) Food consumption frequency and eating habit among Taiwanese - NAHSIT 1993-1996. Nutr Sci J 24, 59-80.

6. Pan WH, Chin CJ, Sheu CT, et al. (1993) Hemostatic factors and blood lipids in young Buddhist vegetarians and omnivores. Am J Clin Nutr 5, 354-359.

7. Chen CW, Lin YL, Lin TK, et al. (2008) Total cardiovascular risk profile of Taiwanese vegetarians. Eur J Clin Nutr 62 , 138-144.

8. Hung CJ, Huang PC, Li YH, et al. (2006) Taiwanese vegetarians have higher insulin sensitivity than omnivores. $\mathrm{BrJ}$ Nutr 95, 129-135.

9. Kuo CS, Lai NS, Ho LT, et al. (2004) Insulin sensitivity in Chinese ovo-lactovegetarians compared with omnivores. Eur J Clin Nutr 58, 312-316.

10. Lu FH, Tang SJ, Wu JS, et al. (2000) Hypertension in elderly persons: its prevalence and associated cardiovascular risk factors in Tainan City, southern Taiwan. J Gerontol A Biol Sci Med Sci 55, M463-M468.

11. Juang SJ, Peng LN, Lin MH, et al. (2010) Metabolic characteristics of breakfast-vegetarian (BV) elderly people in rural Taiwan. Arch Gerontol Geriatr 50, 20-23.

12. Pan WH, Hung YT, Shaw NS, et al. (2005) Elderly Nutrition and Health Survey in Taiwan (1999-2000): research design, methodology and content. Asia Pac J Clin Nutr 14, 203-210.

13. Wu SJ, Chang YH, Wei IL, et al. (2005) Intake levels and major food sources of energy and nutrients in the Taiwanese elderly. Asia Pac J Clin Nutr 14, 211-220.

14. Tsai PS, Ke TL, Huang CJ, et al. (2005) Prevalence and determinants of prehypertension status in the Taiwanese general population. J Hypertens 23, 1355-1360.

15. JNC VII (2004) The Seventh Report of the Joint National Committee on Prevention, Detection, Evaluation, and Treatment of High Blood Pressure. NIH Publication no. 04-5230. Washington, DC: US Department of Health and Human Services.

16. Expert Panel on Detection, Evaluation, and Treatment of High Blood Cholesterol in Adults (2001) Executive summary of the third report of the National Cholesterol Education Program (NCEP) expert panel on detection, evaluation, and treatment of high blood cholesterol in adults (Adult Treatment Panel III). J Am Med Assoc 285, 2486-2497.

17. World Health Organization Western Pacific Region, International Association for the Study of Obesity \& International Obesity Taskforce (2000) The Asia-Pacific perspective: redefining obesity and its treatment. http://www.wpro. who.int/internet/resources.ashx/NUT/Redefining+obesity. pdf (accessed 15 July 2010).

18. Grundy SM, Cleeman JI, Daniels SR, et al. (2005) Diagnosis and management of the metabolic syndrome. An American 
Heart Association/National Heart, Lung, and Blood Institute scientific statement. Circulation 112, 2735-2752.

19. Black AE (2000) Critical evaluation of energy intake using the Goldberg cut-off for energy intake: basal metabolic rate. A practical guide to its calculation, use and limitations. Int J Obes 24, 1119-1130.

20. Mirmiran P, Esmaillzadeh A \& Azizi F (2006) Under-reporting of energy intake affects estimates of nutrient intakes. Asia Pac J Clin Nutr 15, 459-464.

21. Willett W \& Stampfer MJ (1986) Total energy intake: implications for epidemiologic analyses. Am J Epidemiol 124, $17-27$.

22. Appel LJ, Giles TD, Black HR, et al. (2009) ASH position paper: dietary approaches to lower blood pressure. J Clin Hypertens 11, 358-368.

23. Ferdowsian HR \& Barnard ND (2009) Effects of plant-based diets on plasma lipids. Am J Cardiol 104, 947-956.
24. Savica V, Bellinghieri G \& Kopple JD (2010) The effect of nutrition on blood pressure. Annu Rev Nutr 30, 365-401.

25. Joint FAQ/WHO Expert Consultation, Food and Agriculture Organization of the United Nations (2010) Global trends in production and consumption of carbohydrate foods. In Carbohydrates in Human Nutrition. http://www.fao.org/ docrep/w8079e/w8079e0g.htm\#global\%20trends\%20in\% 20 production $\% 20$ and $\% 20$ consumption $\% 20$ of $\%$ 20 carbohydrate\%20foods (accessed 26 October 2010).

26. Ma Y, Li Y, Chiriboga DE, et al. (2006) Association between carbohydrate intake and serum lipids. J Am Coll Nutr 25, $155-163$.

27. Merchant AT, Anand SS, Kelemen LE, et al. (2007) Carbohydrate intake and HDL in a multiethnic population. $\mathrm{Am} \mathrm{J}$ Clin Nutr 85, 225-230.

28. Yeh CY, Liao PS, Liu CY, et al. (2010) An empirical study of Taiwan's food security index. Public Health Nutr 13, 1056-1063. 